\title{
THE EFFECTS OF MECHANICAL AND ENVIRONMENTAL VARIABLES ON FATIGUE CRACK PROPAGATION IN BUTT-WELDED JOINTS
}

S. P. Moghadam and J. C. Radon

Mechanical Engineering Department, Imperial College, London SW7 $2 B X$, England

ABSTRACT

arack growth at low stress intensities has been studied in class 6 weld material in a salt water environment with particular emphasis being hlaced on the influence of stress ratio and frequency Frequency levels of $90 \mathrm{~Hz}$ and $0.25 \mathrm{~Hz}$ Comparing the present results with previously obtained data in air [1] show that in general fatigue crack growth rates were lower andironment than in atress intensity range, $\Delta \mathrm{K}_{\text {th }}$, higher in the salt watim to certain ranges laboratory air This decrease in greng on the stress ratio, and was of stress intensity range, $\Delta \mathrm{k}$, depenting from $30 \mathrm{~Hz}$ independent of frequency. Decreas rates, as a significant increase in growt to $0.25 \mathrm{~Hz}$ had no effect on growh rack growth rates was observed in the data obtain same behaviour in stress-relion in stress intensity range as above except that there was a marked rede proposed to explain the decrease crack closure an

KEYWORDS

(ation fatigue; stress ratio; frequency threshold.

INTRODUCTION

is known that the uclically-loaded welded structures It is known that the usefects is controlled by the crack growth rate and is determined by the growth of the defect to a critical size A knowledge fatigue crack growth rates in weld metal under dilsafe design of welded environment structures. 
Recent experiments from the North Sea show that corrosion fatigue in off-shore structures is a major cause of failures as off-shore structures are subjected to continuous load cycling due to the action of wind and waves in a corrosive environment. Most experimental studies to obtain the effect. and mechanical and environmental variables on fatigue crack propagation rate $[2-4]$; on a few studisis

In previous work [1] fatigue crack propagation in parent plate and butt-welded joints of BS 4360-5OD steel was investigated and it was shown that the fatigue properties of butt-welded joints witiout any post-weld hown that the fatigu superior to those of base metal. This was due to the compressive residual superior to those of base metal. This was due to the compressive residual stresses around the crack tip. The present work was undertaken to investigate the influence of stress ratio, frequency and sea-water on fatigue crack growt butt-welded cond to provide suitable data for ass

\section{Materials And Experimental Details}

The base material was BS 4360-50D steel used in the fabrication of offshore structures. Chemical composition and mechanical properties are in [8].

The blanks for the specimens were prepared by the butt-welding of two plates, each about $50 \mathrm{~mm}$ wide, $95 \mathrm{~mm}$ long and of thickness $25 \mathrm{~mm}$. All the welds were ground flat. The joint preparation was a double 'Vee' and incorporated a $2 \mathrm{~mm}$ root gap. Manual arc-welding and the wide weave technique were employed for manufacturing the specimens using a $\mathrm{C} / \mathrm{Mn}$ welding rod. The chemical composition and mechanical properties of the weld metal are given in Table 1

Standard compact type specimens $79.5 \mathrm{~mm}$ wide were used in the present investigation and notches were orientated parallel to the welding direction and in the weld metal. Some of the welded specimens were stress relieved at $650^{\circ} \mathrm{C}$ for half an hour. The fluid was collected via channels made from a thin aluminium plate and fixed around the specimen. A perspex strip

was fastened to the channel on the side where optical viewing was made, see Figure 1. The salt water was introduced into the notch of the specimen via a thin plastic tube and the flow rate was controlled by gravity feeding

Tests were carried out on a Mayes servo-hydraulic fatigue machine, of $100 \mathrm{kN}$ capacity Near-threshold and regime II fatigue tests were performed in $3.5 \%$ $\mathrm{NaCl}$ solution at stress ratios, $\mathrm{R}$, of 0.08 and 0.7 and loading frequency of $30 \mathrm{~Hz}$ To investigate the effect of frequency in regime II in a salt-water environment, tests were performed at R-values equal to 0.08 and 0.7 , whil the cyclic frequency was reduced to C. $25 \mathrm{~Hz}$

The tests on stress-relieved specimens were performed at stress ratios of 0.7 and loading frequency of $30 \mathrm{~Hz}$ both in air and salt water environments

A travelling microscope was used to reasure the crack length, a, and the stress intensity factor, $\mathrm{K}$, was calculated using the standard formula recommended for compact type geometry

\section{RESULTS}

The effect of stress ratio, $R$, on fatigue crack growth rate of the weldment in salt-water is shown in Figs. 1 and 2 at loading frequencies of $30 \mathrm{~Hz}$ and $0.25 \mathrm{~Hz}$ respectively. At near-threshold stress intensity the crack growth rates and $\Delta K_{t}$ values are strongly dependent on $R$. This effect diminishes with increasing stress intensity range, $\Delta K$, Fig. 1

Reducing the loading frequency from $30 \mathrm{~Hz}$ to $025 \mathrm{~Hz}$ resulted in a slight effect of frequency at high growth rates of the order of 10 $\mathrm{mm} /$ cycle, this is shown in Fig. 3 for stress ratios of 0.08 and 0.7 .

The composite plots of $\mathrm{da} / \mathrm{dN}$ versus $\Delta \mathrm{K}$ in air [1] and this investigation are presented in Figs 4 and 5 . These results indicate that in general crack growth rates in salt solution are lower than the corresponding air dat and in particular there is an increase in $\Delta \mathrm{K}_{\text {th }}$ values from $13.75 \mathrm{MPa} \mathrm{m}$ in air at 0.08 to $22 \mathrm{MPa} \mathrm{m} \mathrm{m}^{\frac{1}{2}}$, and from $6.7 \mathrm{MPa}^{\frac{1}{2}}$ at 0.7 to $9.5 \mathrm{MPa} \mathrm{m}^{\frac{1}{2}}$ in a salt-water environment at $30 \mathrm{~Hz}$. It is interesting to note that the growth rate curves for air and salt-water intersect at the same values of $\Delta K$ at a particular stress ratio irrespective of cyclic frequencies (i.e. $30 \mathrm{~Hz}$
$0.25 \mathrm{~Hz}$ ). These $\Delta \mathrm{K}$ values are approximately $32 \mathrm{MPa} \mathrm{m}^{2}$ at $\mathrm{R}=0.08$ and $20 \mathrm{MPa} \mathrm{m}^{\frac{1}{2}}$ at $\mathrm{R}=0.07$.

Figure 6 shows the result of tests on stress relieved weldments in air and salt-water at $\mathrm{R}=0.7$ and cyclic frequency of $30 \mathrm{~Hz}$, Like the results obtained from as-received welds, it shows crack growth retardation in salt solution Stress relieving appears to reduce the stress intensity factor range $\Delta K$ at a fixed growth rate, if the results are compared with the as-received weld presented in Fig. 4

DISCUSSION

The results obtained at loading frequencies of $30 \mathrm{~Hz}$ and $0.25 \mathrm{~Hz}$ and two Rratios ( $\mathrm{i}$ e $\mathrm{O} 08$ and 07 ) showed a considerable decrease in crack growth rates (see Figs 4 and 5), compared to air data [1]. This effect could be explained in terms of the solution chemistry and the mechanical interaction
between fluid and crack tip geometry [9]. It is possible that due to the nature between fluid and crack tip geometry [9]. It is possible that due to the
of the channels used to collect the fluid, the slow flow rate resulted in of the channels used to collect the fluid, the slow flow rate resulted in
rapid mixing at the crack tip and in the bulk solution. This mixing process rapid mixing at the crack tip and in the bulk solution. This mixing process tip and/or the possibility of the used fluid and corroded products being tip and/or the possibilty of the used fluid and corrode products in the deposited at the crack tip and causing blunting which in tur growth rates At lower values of $\Delta k$ the growth rate is low and blunting of $\Delta K$ the growth rates are faster and it is possible that in this range the environmental action complements the mechanical stresses to enhance growth rates.

Tu and Seth [10] explained the retardation of fatigue cracks in corrosive environments at low $\Delta K$ values in terms of deposited corrosion products at the crack tip which will form a protective film and effectively reduce the amount of further corrosion agent entering the crack tip, thus causing a slower crack growth rate at low values of $\Delta K$ and thresholds. At high values of $\Delta K$ where
the growth rate is higher, the corrosion products do not have enough time to pile up, and corrosive agents can enter the fresh fracture surfaces 
2002

created during the loading cycle to cause further embrittlement without delay

Radon and co-workers [11] suggested a dissolution process which leads to crack blunting, this mechanism being responsible for the low crack growth rate in sodium chloride solution compared with air at low test frequencies The dissolution process contributes mainly by increasing the radius curvature at the crack tip, which at high growth rates means that a longer time will be required, since a larger volume of material will have to be moved Thus high growth rates do not favour crack tip blunting. This explanation agrees well with the present results, as there is less retardation at high growth rates

Previous work by Rhodes and Radon [12] suggested two distinct processes by which crack propagation may occur. One is due to chemical action at the crach tip enhanced by the presence of a tensile stress, referred to as stressassisted dissolution' The other is due to local mechanical failure, enhanced by the presence of an adverse environment, 'environment assisted fracture' These two processes are mutually competitive. Stress assisted dissolution, by the action of microbranching and blunting, actually inhibits mechanical fracture Conversely, if mechanical failure proceeds sufficiently rapidly, there is no time for dissolution to take place before the crack-tip passes any particular point in the material This the two procasses are not pinply

In the present investigation it appears that stress-assisted dissolution has dominated the process of crack growth. However, no fractographic examination was made, thus the mechanics of microbranching cannot be confirmed in this wady. Crack closure phenomena due to Elber [13] have often been used to explain the observed effect of stress ratio on fatigue crack growth rates. According to this concept, the crack closure stress intensity factor $k$ According to this concept, the crack closure stress intensity factor ${ }^{K} \mathrm{C}$

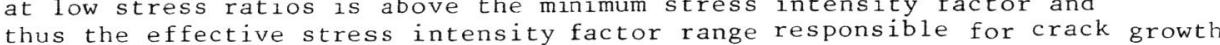
thus the effective stress intensity factor range responsible for crack growt the whole or larger part of the load cycle and thus the crack closure effect becomes less pronounced; in other words, the contribution of fatigue crack extension may take place only during those portions of the cycle where the crack remains open. This argument seems to explain the effect of $\mathrm{R}$ ratios for the present results. In Figs, 1 and 2 a decrease of growth rate with decreasing R-ratio was observed for a given value of $\Delta \mathrm{K}$.

The data summarised in Fig. 3 shows that frequency effects occur only at high growth rates. At near-threshold and intermediate $\Delta \mathrm{K}$ values, the growth rates appear to be the same. This observation conforms with those of other investigators [14, 15]. The results suggest two distinct regions [15] which are identified as frequency-independent and frequency-dependent regions I and II respectively In region I where the growth rate is only $\Delta \mathrm{K}$ dependent, the exposure of clean metal surfaces at the crack tip is a rate controlling step. In region II where the crack growth rate is only frequency dependent, it is likely that some reaction-step in hydrogen-metal interaction at the crack-tip controls the growth rate.

\section{CONCLUSIONS}

As a result of a study of the effect of environment on fatigue crack growt in butt-welded joints, the following conclusions may be drawn

1. Fatigue crack growth ratios are, in general lower, and threshold $\Delta \mathrm{K}_{\text {th }}$ values are higher in salt water solution than in air. cock growth continues at a reduced rate, critical value of $\Delta K$ exists irrespective of loading frequency beyond which rapid growth ${ }_{1}$ ensues This $\Delta \mathrm{K}$ value is approximate $r$ and salt water environment curves

3. Stress ratio, $R$, was found to influence the fatigue crack growth rate in salt solution, increased $R$ values being accompanied by increased growth rate A frequency effect is not significant in a salt water environment for the welds used in this study

Stress relieving does not change the shape of the curves in air and sal water; it only reduces the stress intensity range $\Delta \mathrm{K}$

\section{REFERENCES} 1. Moghadam, S. P, Balthazar, J C, and Radon, J C, (1984). Fatigue crack propagation in the parent matere Prevention in Energy and Transport Systems, Rio de Janeiro

Musuva, J K and J C Radon (1981) Threshold of fatigue crack grow 2 Musuva, $\mathrm{J} \mathrm{K}$, and $\mathrm{J}$. Radon in Fracture Mechanics, 5 th Int Conf on Fract, Cannes pp. 1365-1372

3 Radon, J C (1979). Influence of environment on threshold in fatigue crack growth Metal Science, 13, pp 411-419

4 Paris, P.C, Bucci, R J , Wessel, E T., Clark, W G and Mager, T R (1972) Extensive study of low fatigue

Fatigue crack propagation in weld metal and heat

5. Maddox, S (1970) Fatigue crack propagation in we 1d metal and he

affected zone material Metal Const. \& B Weld. J., 2, pp. 285-289

$\begin{array}{lll}\text { 6. Sandifier, J.P. and Bowie, G E } & (1978) \\ \text { in } & \text { (1937M steel. ASTM STP 648, PP } & 185-196\end{array}$

in A $537 M$ steel. ASTM STP 648 , PP 185-196.

7. Poon, C J and Hoeppmer, D. W. (1979). The effect of frequency and environment on fatigue crack growth behaviour of

1 weldment material (1982) Basic Tensile Properties of a 8. Zheng, C.Q, and Radon, J.C. (1982) Material Evaluation and Structure Design, Melbourne, Australia, pp $243-256$ 9. Hartt, W.H., Tennant, J.S and Hopper, W.C. (1978) Solution che
. S modification with corrosion fatigue cracks. 10. Tu, L.K. L., and Seth, B. B. (1978) Threshold

in steels $\mathrm{J}$ of Testing \& Eval,

1. Radon, J C., Branco, C M. and Culver, L.E (1976) Mech, 12, pp. 467-469 
12. Rhodes, D., and Radon, J.C. (1979). Environmental effects on crack propagation in aluminium alloys. Fatigue of Eng. Mater and Struct, 1, PP. $383-393$

13. Elber, W., (1971). The significance of fatigue crack closure. ASTM STP 486 pp. $230-242$.

14. Musuva, J.K. and Radon, J.C. (1979): The effect of stress ratio and requency on fatigue crack growth. Fatigue of Eng Mater.\& Struct 1 , pp. $457-470$

15. Vosikovsky, O (1975). Fatigue crack growth in an X-65 line pipe steel at low cyclic frequencies. J. Eng. Mater, \& Tech., 97, pp. 298-304.

\section{TABLE 1}

Welding Electrode BS 639 : E 4311 R21 (3)

Chemical Composition (Weight)

Element

\begin{tabular}{|c|c|c|c|}
\hline c & $\mathrm{Mn}$ & $\mathrm{Si}$ & $\mathrm{s}$ \\
\hline 0.06 & 0.58 & 0.43 & $0.02 \max$ \\
\hline \multicolumn{4}{|c|}{ Mechanical Properties } \\
\hline \multicolumn{4}{|c|}{$\begin{array}{l}\text { Yield Strength } \mathrm{N} / \mathrm{mm}^{2} \\
\text { UTS } \mathrm{N} / \mathrm{mm}^{2}\end{array}$} \\
\hline \multicolumn{4}{|c|}{$\%$ Elongation } \\
\hline$\% \operatorname{Re}$ & tion of & & \\
\hline
\end{tabular}

Charpy V-notch at RT $\left(20^{\circ} \mathrm{C}\right) 80$ joules

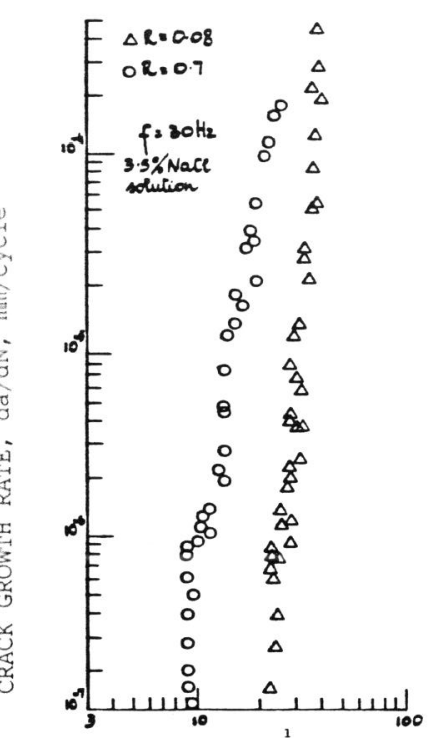

$\triangle K\left(\right.$ MPa $\left.\mathrm{m}^{\frac{1}{2}}\right)$

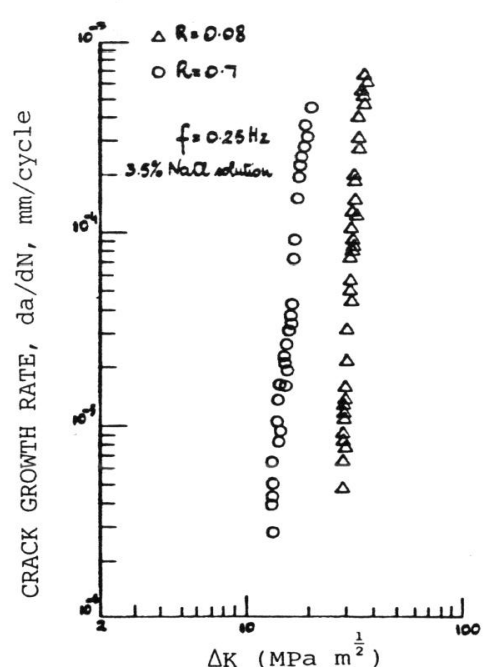

$\triangle \mathrm{K}\left(\mathrm{MPa} \mathrm{m}^{\frac{1}{2}}\right)$
. Stress ratio effect on weldment on weldment in salt solution using CT specimen in salt solution at

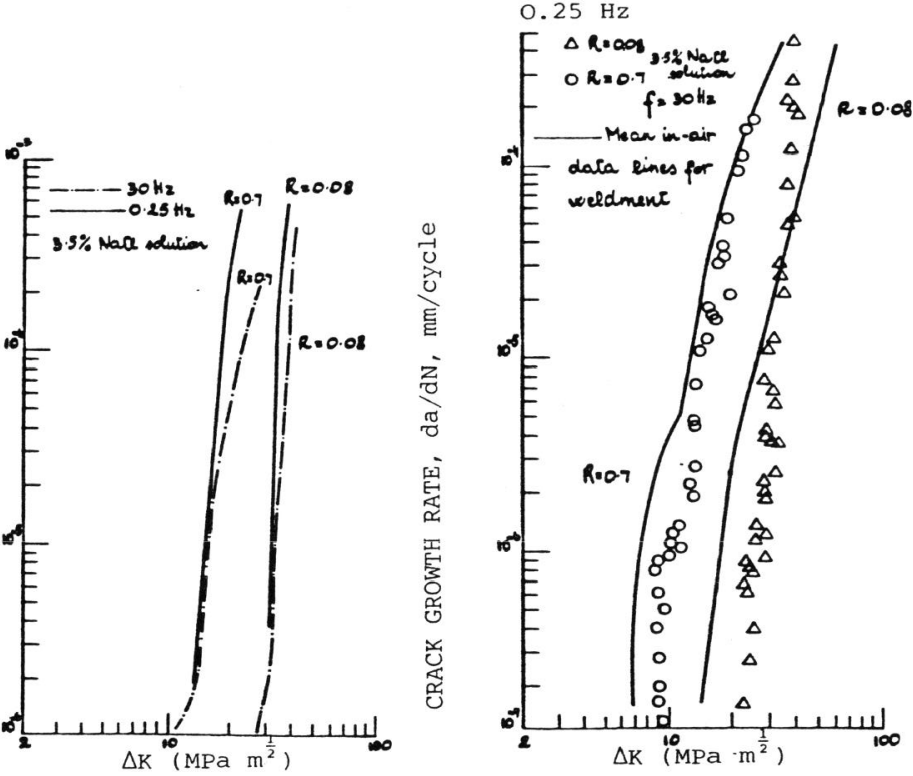

Fig. 3. Frequency and stress ratio effects on weldment in salt solution
Fig. 4. Stress ratio effect on weldment in air and salt solution 


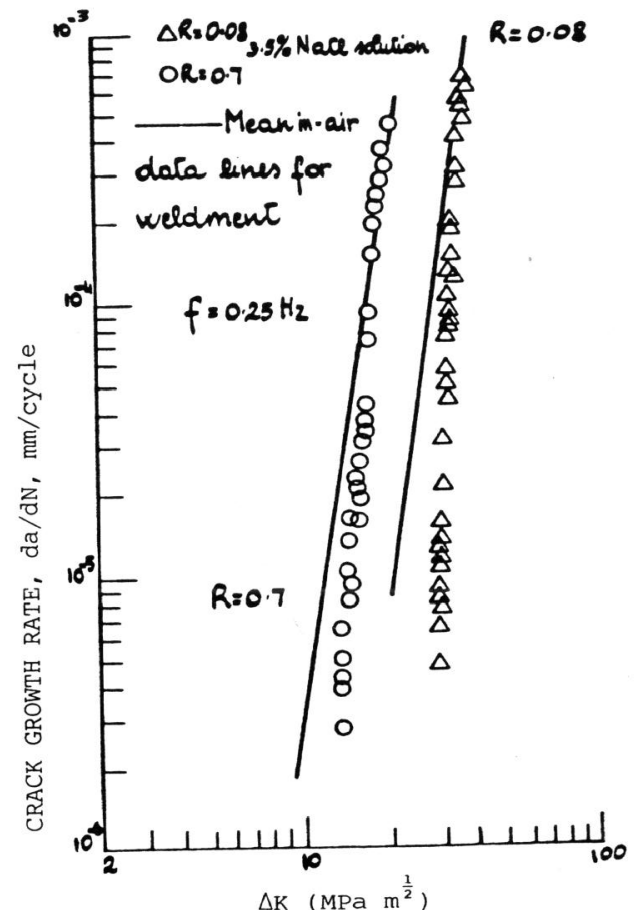

$\Delta K \quad\left(\right.$ MPa $\left.m^{\frac{1}{2}}\right)$

Fig. 5. Effect of Stress ratio on weldment in air and salt solution

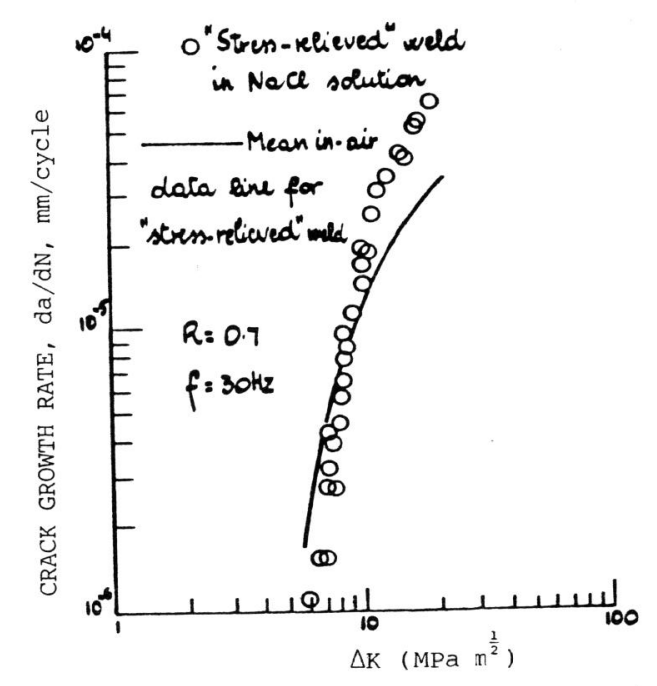

Fig. 6. Stress relieved weldment in air and salt solution 